\title{
Proteoglycan Breakdown of Meniscal Explants Following Dynamic Compression Using a Novel Bioreactor
}

\author{
J. A. McHenry, Barbara Zielinska, and T. L. Haut Donahue \\ Department of Mechanical Engineering, Michigan Technological University, Houghton, MI 49931, USA
}

(Received 21 March 2006; accepted 14 August 2006; published online: 10 October 2006)

\begin{abstract}
Motivated by our interest in examining meniscal mechanotransduction processes, we report on the validation of a new tissue engineering bioreactor. This paper describes the design and performance capabilities of a tissue engineering bioreactor for cyclic compression of meniscal explants. We showed that the system maintains a tissue culture environment equivalent to that provided by conventional incubators and that its strain output was uniform and reproducible. The system incorporates a linear actuator and load cell aligned together in a frame that is contained within an incubator and allows for large loads and small displacements. A plunger with six Teflon-filled Delrin compression rods is attached to the actuator compressing up to six tissue explants simultaneously and with even pressure. The bioreactor system was used to study proteoglycan (PG) breakdown in porcine meniscal explants following various input loading tests (0-20\% strain, $0-0.1 \mathrm{MPa})$. The greatest PG breakdown was measured following $20 \%$ compressive strain. These strain and stress levels have been shown to correspond to partial meniscectomy. Thus, these data suggest that removing 30 $60 \%$ of meniscal tissue will result in the breakdown of meniscal tissue proteoglycans.
\end{abstract}

Keywords-Apparatus, Mechanotransduction, Meniscectomy.

\section{INTRODUCTION}

Mechanical loading of the meniscus plays a crucial role in the metabolic activity of fibrochondrocytes. $^{7,11,12,15}$ Previous studies have demonstrated that increased load on meniscal tissue leads to an increase in proteoglycan and collagen levels, ${ }^{16}$ whereas unloading of meniscal tissue causes a decrease in aggrecan expression, collagen formation and cell growth. ${ }^{2,3}$ It is not fully understood how biomechanical and biochemical events interact to produce changes in the extracellular matrix. This lack in knowledge is,

Address correspondence to T. L. Haut Donahue, Department of Mechanical Engineering, Michigan Technological University, Houghton, MI 49931, USA. Electronic mail: thdonahu@mtu.edu in part, due to the difficulties associated with performing real time meniscal loading experiments in vivo.

Recreating the physiological forces in vitro using tissue explants while measuring the biological response provides one method for observing the effect of mechanical stress on the meniscus; ${ }^{9,15}$ however, the majority of commercially available bioreactors may not be suitable for application to meniscal loading studies. The Biopress system (The Biopress system, Flexcell International, Hillsborough, NC, USA) uses air pressure applied to a flexible bottom under each well. The Biopress has been used to apply pressures of $0.1 \mathrm{MPa}$ in previous studies on meniscal explants, 7,15 noting strain levels of approximately $10 \%$. Because pressures up to $10 \mathrm{MPa}$ and strains ranging from $2 \%$ to $20 \%$ are seen in the meniscus ${ }^{13,18}$ this system may not generate high enough pressures to mimic the full range of meniscal strains thought to occur during active loading of healthy and damaged tissue in vivo. Stresses and strains are approximately $5-10 \%$, and $3 \mathrm{MPa}$, respectively, in the normal healthy meniscus, but these strain levels increase with a partial meniscectomy to approximately $20 \%$ and $8 \mathrm{MPa} .{ }^{18}$ Another biaxial tissue-loading device, previously used to compress articular cartilage explants, is able to create a maximum $400 \mathrm{~N}$ axial force on as many as 12 explants at once, however, is limited to $100 \mu \mathrm{m}$ of motion. ${ }^{8}$

Previous studies have shown that following knee trauma, such as ACL transection, prior to any articular cartilage damage, there are signs of meniscal tissue degeneration. ${ }^{10}$ We have previously shown that following partial meniscectomy, the remaining meniscal tissue is subjected to an altered loading state. ${ }^{18}$ This altered loading state may cause a direct breakdown of matrix components such as proteoglycans (PG), or indirectly affect matrix production by induction of catabolic biomolecules.

The objectives of this study were (1) to design and build a practical, cost-effective device for applying homogeneous strains to tissue explants, and (2) to 
utilize the system to overload and underload meniscal tissue and measure the biochemical output. In this communication, we show that the ensuing device is a simple biocompatible design that applies accurate and reproducible strains and is made of components that can be sterilized. We utilized the bioreactor to apply both load and displacement controlled dynamic compression tests. Dynamic strain compression tests showed PG breakdown following overloading of meniscal tissue. No significant changes in concentration of PG released to the conditioned media was measured following various levels of dynamic compressive stress. A comparison between stress controlled dynamic compression versus strain controlled dynamic compression was also made.

\section{MATERIALS AND METHODS}

\section{Design of Bioreactor}

The frame consists of two $2.54 \mathrm{~cm}$ thick parallel aluminum plates separated by $2.54 \mathrm{~cm}$ diameter aluminum support rods (Fig. 1). Centered on the bottom plate is a load cell that is attached to a six well dish. The system is driven by a belt-driven linear actuator utilizing a control package by Animatics (Smartmotor 1720, Ultramotion, Mattituck, NY, USA). The actuator has a maximum stroke length of $5 \mathrm{~cm}$ and can thrust to
$2225 \mathrm{~N}$. It also has a maximum speed of $50 \mathrm{~cm} / \mathrm{s}$ with bi-directional repeatability of $\pm 0.00762 \mathrm{~mm}$ and a unidirectional repeatability of $\pm 0.00254 \mathrm{~mm}$. Motor control was achieved by using the SmartMotor Interface (SMI). This language allows the motion of the actuator to be controlled by the signal generated by the load cell or by the displacement of the actuator. Displacement resolution for the actuator is $0.4 \mu \mathrm{m}$.

A strain gage load cell (Model 1210AF, Interface, Scottsdale, AZ) with a load capacity of $1334 \mathrm{~N}$ (sensitivity of $\sim 1.3 \mathrm{~N}$ ) was utilized. For tests that require loads near or above $1334 \mathrm{~N}$, a dimensionally identical load cell with $8896 \mathrm{~N}$ (sensitivity $\sim 2.17 \mathrm{~N}$ ) (Interface, Scottsdale, AZ, USA) capacity is interchangeable with the current load cell. This design feature of interchangeable load cells allows for a larger range of loads to be accurately measured. A 2100 series signal conditioner (Vishay Instruments, Raleigh, NC, USA) amplifies the load cell signal to produce a $5 \mathrm{~V}$ signal at the maximum load.

The load cell is centered on a $2.54 \mathrm{~cm}$ thick aluminum plate that is the base of the system frame. A threaded stud leaving the load cell connects to the aluminum dish via a quick disconnect pin. The dish has six $10 \mathrm{~mm}$ deep wells equally spaced in a circular orientation. Teflon-filled Delrin compression rods (diameter $=8 \mathrm{~mm}$ ) for each well are press fit into a plunger which attaches to the actuator via a quick

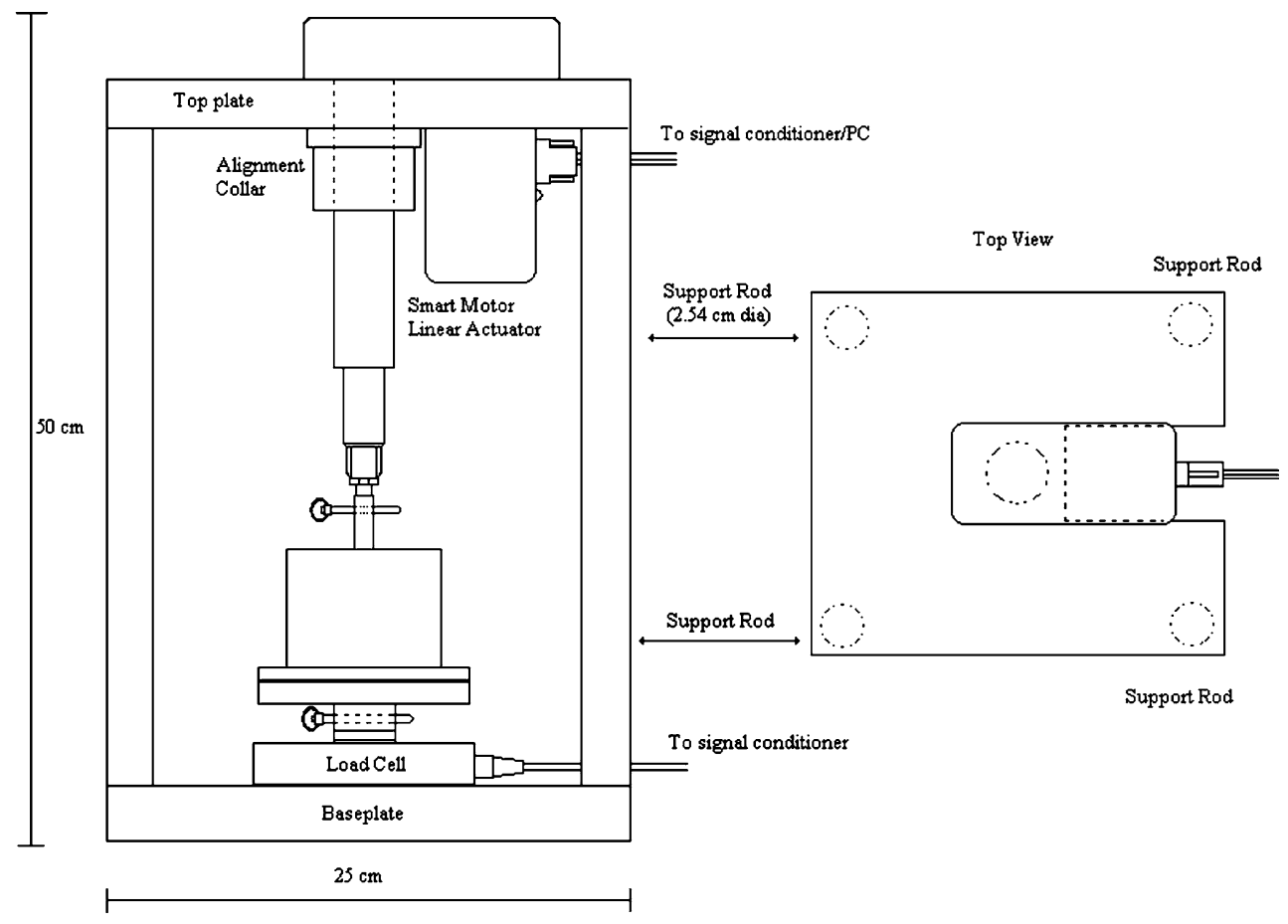

FIGURE 1. A 2-dimensional view of the assembly of the plunger, dish, and cap. The test frame is composed of two aluminum plates supported by aluminum rods. The actuator is positioned in a centered hole in the top plate and tighten into alignment with an adjustable collar. 
disconnect pin. To ensure only one plunger/dish orientation and to keep the compression rods centered in each well, the plunger also features two press-fit aluminum pins that slide into matching holes in the dish. An aluminum cap rests on the shoulder of the dish and houses a linear bearing that is press fit into the cap. Along the resting edge of the cap, four shallow grooves were machined to allow carbon dioxide supply to the explants during testing. The linear bearing allows the plunger to move up and down within the cap and restricts the plunger to vertical motion (Fig. 2). The entire frame is small enough that it can be placed in a commercially available $\mathrm{CO}_{2}$ incubator to maintain physiological conditions (Model 5015, VWR, West Chester, PA, USA).

\section{Accuracy Evaluation of the System}

Ultra-low pressure film (Sensor Products Inc., East Hanover, NJ, USA) was used to measure well pressure during compression. First, the repeatability of the pressure film was tested by loading the film (seven times) between flat platens in a tensile testing machine (Model 8872, Instron Corp., Canton, MA, USA) to a $70 \mathrm{~N}$ target load, corresponding to a pressure of $0.477 \mathrm{MPa}$ for the given indentor size. Calibration of the pressure film was also done using the tensile testing machine and included loading pieces of pressure film ranging from 0.2 to $1.64 \mathrm{MPa}$. Pressure film analysis was completed using commercial software (Scion
Image, National Institute of Standards and Technology, Gaithersburg, MD, USA) to measure the density of the pressure film samples. Film was compressed between the platens and a piece of rubber similar to the rubber used for testing well pressure.

To determine well pressure in the bioreactor, a machined plate was set on top of the dish with a $3 \mathrm{~mm}$ thick piece of uniform rubber. Pressure film was placed on top of the rubber and the plunger was lowered near the surface of the film. Four tests were conducted, each to the same pressure $(0.477 \mathrm{MPa})$ to determine the repeatability of the bioreactor in load control. The film from the bioreactor was analyzed and density measured to determine the difference between each compression rod. The difference in film density and the maximum percentage error was determined to demonstrate the accuracy of the system.

\section{Determination of Displacement Repeatability}

To further investigate the accuracy of the system, the gap between the bottom of the compression rods and the bottom of the wells was measured while the system was assembled into the bioreactor. This was done by using the actuator to compress commercially available Fibre-Strand body filler (6371, The Matin Senour Comp., Cleveland, OH, USA) until the gap between the bottom of the compression rod and well bottom was filled. The actuator remained at this position until the body filler hardened completely.

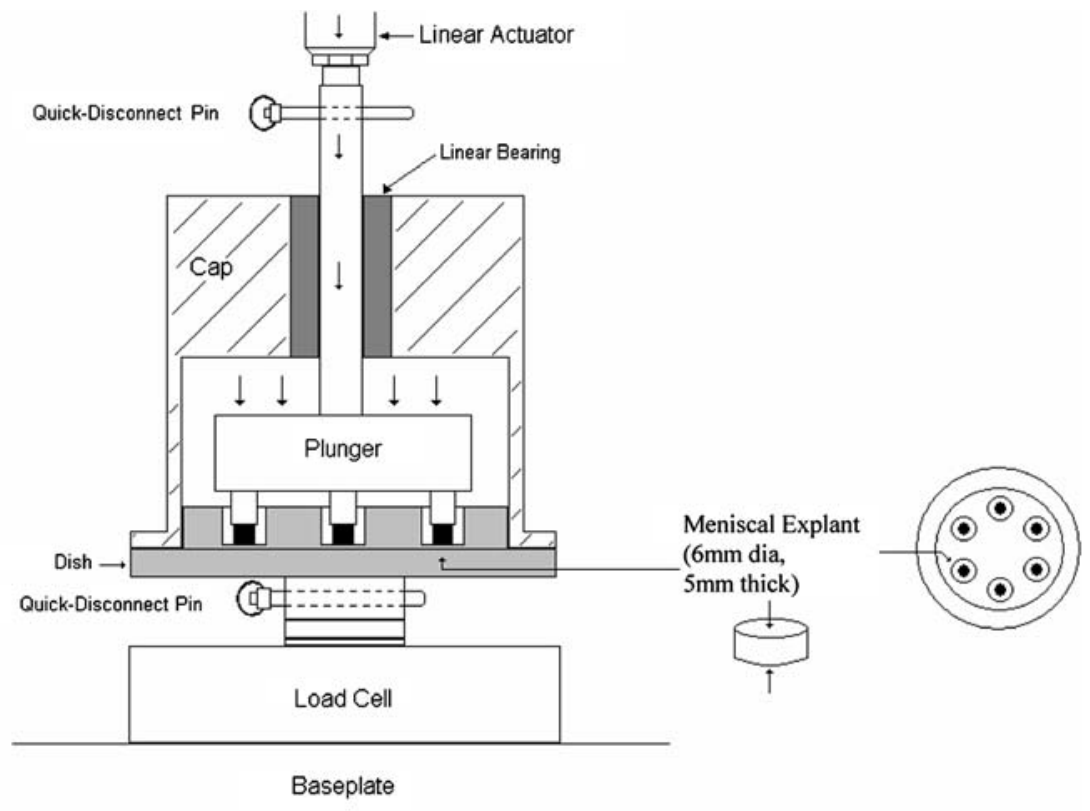

FIGURE 2. A 2-dimensional drawing of the test frame shows the side and top view of the test system. The linear actuator is attached to the plunger using a quick-disconnect pin. The dish is attached to the load cell in the same manner. The cap improves alignment of the plunger by utilizing a linear bearing. 
After plunger removal, a micrometer $(2.54 \mu \mathrm{m}$ resolution) was then used to measure the thickness of the body filler. This process was repeated three times with the same plunger and dish orientation.

\section{Compliance of the System}

The compliance of the system was determined by placing a flat stainless steel plate over the wells and running a load-deformation test in the absence of menisci. The test was repeated three times and the load-deformation data recorded.

\section{Application of the System}

Pigs used in the experiment were 18 weeks old, sacrificed $24 \mathrm{~h}$ after death (received from Mayo Clinic, Rochester, MN, USA). The explants were collected from both the lateral and medial meniscus using sterile technique. The explants were $6 \mathrm{~mm}$ in diameter and cut using a biopsy punch, perpendicular to the superior surface to maximize the amount of superior tissue preserved. To ensure two parallel flat faces on the cylindrical explants, a specialized cutting device was utilized. Explants were held such that a fixture containing two razorblades, $5 \mathrm{~mm}$ apart, cut the tissue perpendicular to the long axis of the cylindrical explant. This ensured that each explant was the same height with parallel faces (Fig. 3a).

Explants were incubated at $37^{\circ} \mathrm{C}\left(5 \% \mathrm{CO}_{2}\right)$ for $48 \mathrm{~h}$ in growth media (89\% DMEM/F-12, 10\% FBS, $1 \%$ Penn/ Strep) which was changed after $24 \mathrm{~h}$. For mechanical testing, the explants were placed in the six well bioreactor filled with $400 \mu \mathrm{l}$ of the test media (97\% DMEM/F-12, $2 \%$ FBS, $1 \%$ Penn/Strep). The explants were loaded for $2 \mathrm{~h}$ at $1 \mathrm{~Hz}$, at one of the following levels: $5 \%, 10 \%, 15 \%$ or $20 \%$ strain, 0.05 or $0.1 \mathrm{MPa}$ unconfined dynamic compression. Each loading group consisted of six explants taken from six different animals (except $15 \%$ test -4 animals). Control explants were placed in wells, but not exposed to compression. Previous experiments (FE analyses) showed that under two times body weight the intact knee meniscus experiences about $10 \%$ maximum compressive strain. Removal of $5-10 \%$ of the meniscus minimally affects the maximum strain level, however, removal of $30-60 \%$ of the meniscal body increases the maximum strain to $15 \%$ or greater. Generally speaking, $0 \%$ strain is likely underloading the tissue, $5-10 \%$ is approximately physiological and $15-20 \%$ is considered overloading ${ }^{18}$ (Fig. 3b). Following compression the explants were bisected into superior and deep zone, by cutting them in half (Fig. 4), weighted and placed in 24-wells plates, in $1 \mathrm{ml}$ of fresh test media. Samples were post-incubated at $37^{\circ} \mathrm{C}\left(5 \% \mathrm{CO}_{2}\right)$ for $24 \mathrm{~h}$. Post-incubation media was collected and stored at $-80^{\circ} \mathrm{C}$ for future analysis.

The content of sulfated glycosaminoglycan (GAG) released to the conditioned media was assayed using dimethylmethylene blue (DMMB) dye solution. ${ }^{5,6}$ The standard curve was generated with a known concentration of shark cartilage chondroitin sulfate C. All samples were run in duplicates. The concentration was normalized to the wet weight of the explant. GAG release was then normalized to the no load control samples for each animal.

\section{Data Analysis}

The concentration of the GAG released to the media was calculated using a standard curve $\left(R^{2}>0.85\right)$. The final value was an average from duplicates. All data is presented as mean \pm standard error. A one way ANOVA followed by Fisher's PLSD post-hoc testing was used to measure statistical differences $(p<0.05$ was considered significant). Paired t-tests were used at each stress or strain level to determine differences between superficial and deep zone PG release to the media.

\section{RESULTS}

\section{Accuracy Evaluation of the System}

The repeatability test showed an average of $0.4773 \pm 0.0003 \mathrm{MPa}$. The pressure film demonstrated
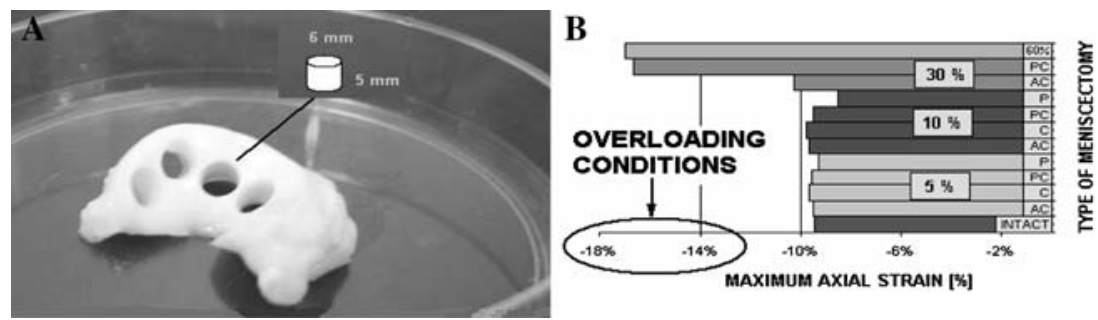

FIGURE 3. a - Meniscus following biopsy, b - Maximum axial strain following different partial meniscectomy simulated by FE analysis. Various percentages $(5 \%, 10 \%, 30 \%$ and $60 \%)$ removed from different portion of the medial meniscus (A - anterior, $\mathrm{C}-$ central, $\mathrm{P}$ - posterior). Knee loaded with $1200 \mathrm{~N}$ axial force. 


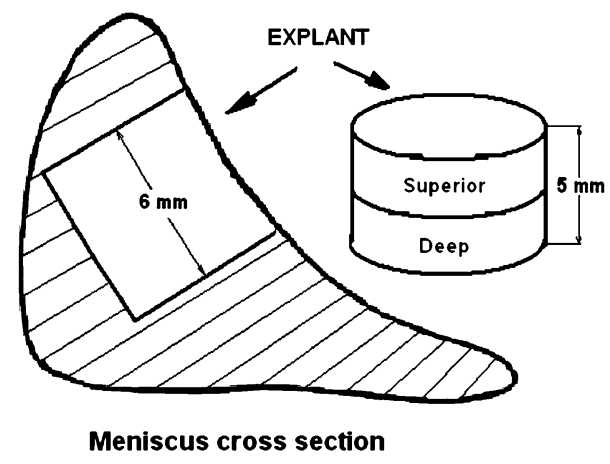

FIGURE 4. Cross-section of the meniscus with the direction of the cut and explants showing superior and deep zones.

equal pressure in each well for each load (Fig. 5). There was less than a $1 \%$ error (Table 1 ).

\section{Determination of Displacement Repeatability}

The micrometer measurements from the body filler showed that the bioreactor was extremely repeatable. Well 3 had the largest standard deviation in height, $3.4 \pm 0.01 \mathrm{~mm}$, whereas well 1 had the lowest standard deviation $3.4 \pm 0.0015$.

\section{Compliance of the System}

The results of the compliance test indicate a linear load-deformation response $\left(R^{2}>0.99\right)$. The slope of the load-deformation curve was $3465 \pm 200 \mathrm{~N} / \mathrm{mm}$. Thus, for the range of strains and stresses seen in this study, the compliance is negligible.

\section{Application of the System}

To determine an appropriate post incubation time, preliminary tests were run. PG concentration in the
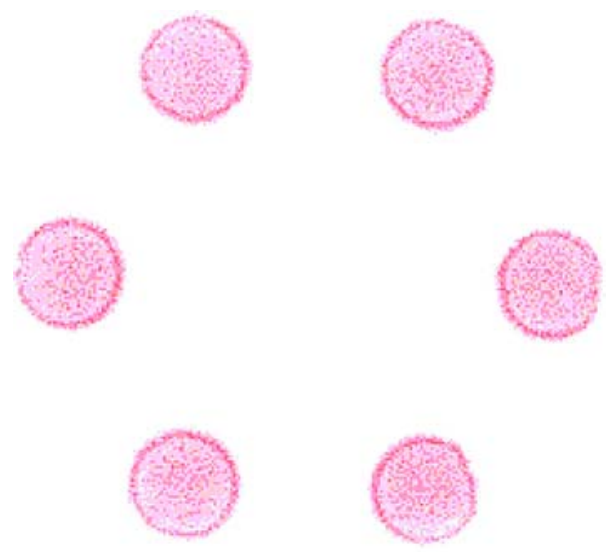

FIGURE 5. Pressure film impressions at $0.477 \mathrm{MPa}$ under the six bioreactor compression rods. media was monitored following 2, 4, and $6 \mathrm{~h}$ and 1,2 , and 3 days following $10 \%$ dynamic compression and for controls samples (Fig. 6). The shortest time showing a strong signal was chosen to minimize the duration of the experiment (1 day).

The highest break down of PG was measured following $20 \%$ compressive strain for both the superior and deep zones of the meniscal explants (Fig. 7). There were significant differences between release of GAGs into the media for the overloaded condition $(20 \%)$ versus physiological loading $(10 \%)$ for both superior and deep zones. No significant differences were found between superficial and deep zones for any compression level. Explants exposed to pressures of either 0.05 or $0.1 \mathrm{MPa}$ did not show any significance differences in either the superior or deep zone for PG breakdown (Fig. 8).

Displacement controlled tests showed a rapid drop in load within the first 1000 cycles with little change in the following 6200 cycles (Fig. 9). For displacement tests at or below $15 \%$ strain, loads settled just below $0.05 \mathrm{MPa}$ while the $20 \%$ strain test remained above $0.1 \mathrm{MPa}$ throughout the duration of the test. The change in pressure measured from the beginning of the test to the end is shown in Table 2. Load controlled tests (Fig. 10) showed a rapid increase in compressive displacement within the first 2000 cycles. The $0.05 \mathrm{MPa}$ load level reached maximum displacement near 3000 cycles and remained at that level to the end of the test. The $0.1 \mathrm{MPa}$ tests reached $18 \%$ strain near 3000 cycles but steadily increased to $20.7 \%$ strain by the final cycle. The differences in strain from the start to the end of the tests can be found in Table 3 .

\section{DISCUSSION}

The explant compression system meets the criteria necessary to obtain a realistic representation of physiological forces present in the knee joint. This system is able to apply known pressures to six explants at once, which is important when trying to gather data for hypothesis testing. It is capable of applying physiological and supraphysiological levels of load and displacement, and has the ability to test in load or displacement control. SMI programming allows for flexibility in frequency, duration, amplitude, and waveform. The system is small enough to fit in a standard incubator and is made of materials that can endure autoclaving and alcohol. An important feature to this system is the ability to keep the explants and media sterile from the culture hood to the incubator. The plunger, dish, and cap form an enclosure that allows easy transport between the culture hood and incubator without allowing open air and bacteria to 
TABLE 1. Results of pressure film verification.

\begin{tabular}{|c|c|c|c|c|c|c|c|c|}
\hline \multirow{2}{*}{$\begin{array}{l}0.477 \mathrm{MPa} \\
\text { Test \# }\end{array}$} & \multicolumn{8}{|c|}{ Pressure (MPa) } \\
\hline & Rod 1 & Rod 2 & Rod 3 & Rod 4 & Rod 5 & Rod 6 & Average & Std. Dev. \\
\hline 1 & 0.4773 & 0.4768 & 0.4771 & 0.4771 & 0.4768 & 0.4768 & 0.4770 & 0.0002 \\
\hline 2 & 0.4768 & 0.4769 & 0.4768 & 0.4768 & 0.4769 & 0.4772 & 0.4769 & 0.0001 \\
\hline 3 & 0.4773 & 0.4768 & 0.4769 & 0.4770 & 0.4769 & 0.4771 & 0.4770 & 0.0002 \\
\hline 4 & 0.4773 & 0.4768 & 0.4769 & 0.4768 & 0.4769 & 0.4768 & 0.4769 & 0.0002 \\
\hline
\end{tabular}

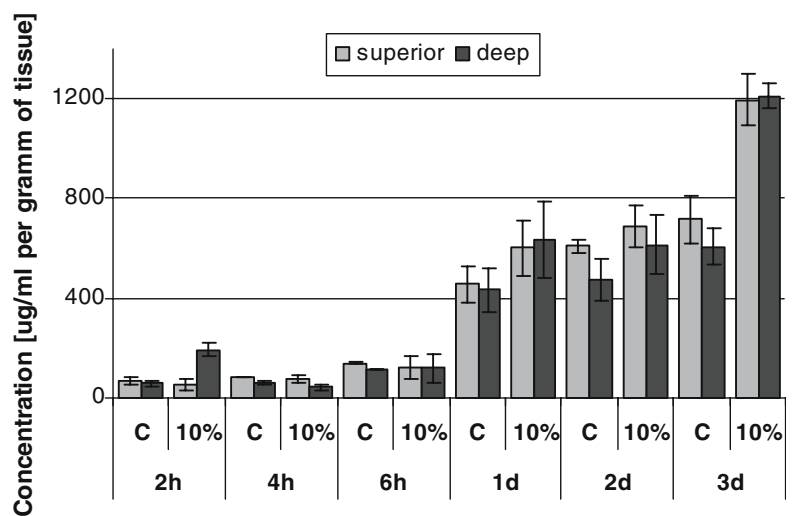

FIGURE 6. PG concentration following different incubation time ( $n=2$ for controls (C), $n=3$ for $10 \%$ compression test $(10 \%))$. Data presented is mean \pm standard error.

infect the sample. Since the cap incorporates a linear bearing it does not need to be removed for testing. Utilizing the system features and designing the correct protocol will help maintain a physiological loading sterile environment.

This bioreactor is capable of creating higher loads and greater displacements than previous systems used for compressing explants. ${ }^{7,8,15}$ The Biopress system (Flexcell International, Hillsborough, NC, USA) is capable of loads as high as $69 \mathrm{~N}$, whereas the current systems actuator can thrust to $2225 \mathrm{~N}$. An advantage

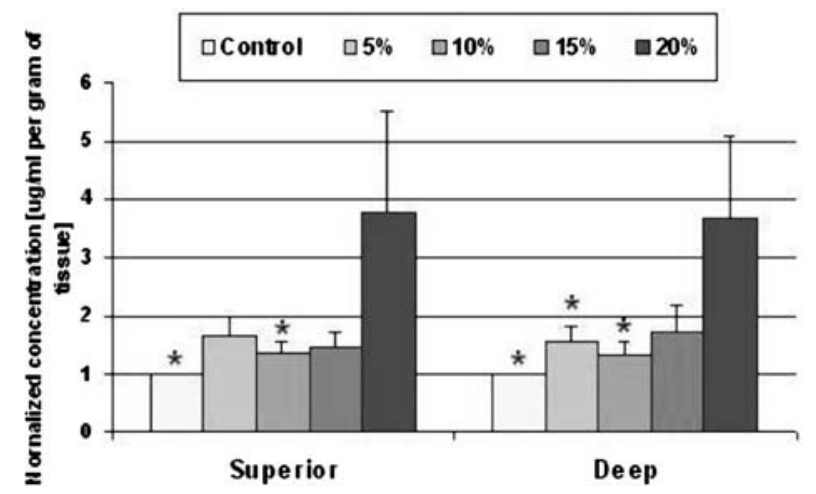

FIGURE 7. PG concentration following different compression tests $(n=6$ except $15 \%$ test $(n=4))$. Data presented is mean \pm standard error. *Statistically different than $20 \%(p<$ 0.05).

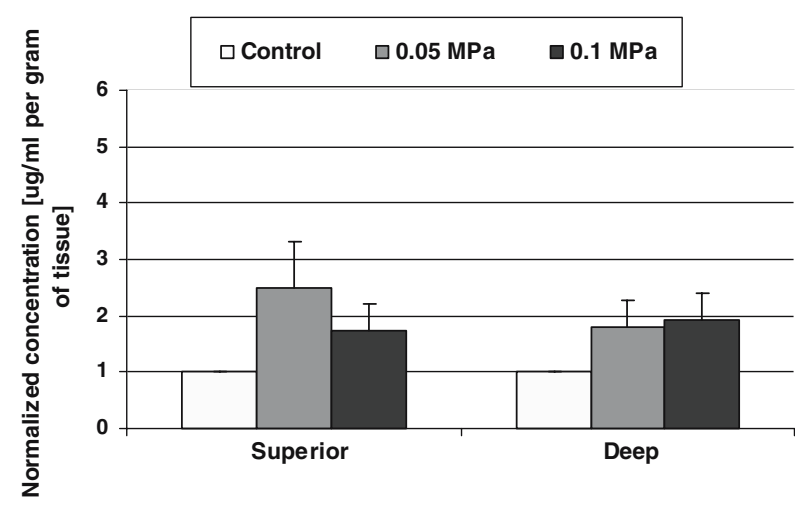

FIGURE 8. PG concentration following different load level compression tests $(n=6)$. Data presented is mean \pm standard error.

of our system over the biaxial tissue-loading device presented in Frank et al. (2000), is that it can create displacements over $10 \mathrm{~mm}$ with a resolution of $0.4 \mu \mathrm{m} .{ }^{8}$ Our actuator also has a bi-directional repeatability of $\pm 7.62 \mu \mathrm{m}$ compared to the $\pm 25 \mu \mathrm{m}$ used in Sah et al. (2003). ${ }^{11}$ In addition, the present system is capable of $1 \mathrm{~Hz}$ cyclic compression in a sinusoidal wave using displacement or load control. The bioreactor can be used to compress any tissue that fits under an $8 \mathrm{~mm}$ compression rod and in a $10 \mathrm{~mm}$ deep well. All surfaces are machined to a smooth,

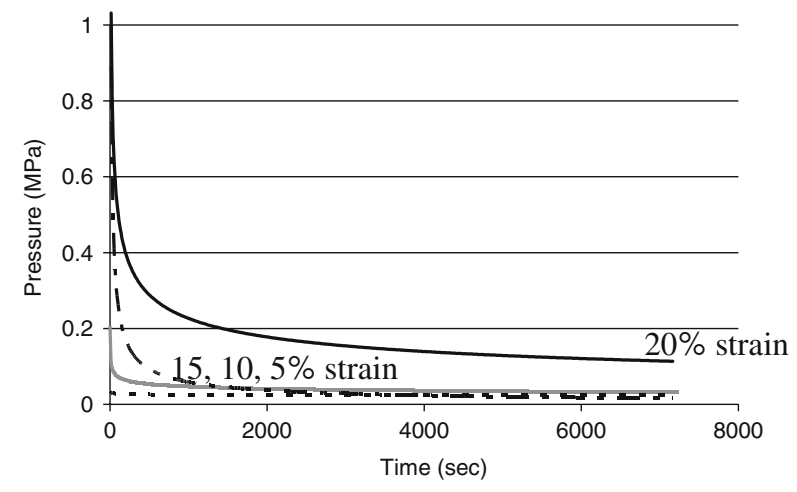

FIGURE 9. Stress vs. time for four representative displacement control tests. Only peak values during each cycle are plotted. Stress was calculated by dividing the peak load by the initial cross-sectional area. 
Table 2. Change in pressures over the duration of the stressrelaxation tests.

\begin{tabular}{lcc}
\hline & \multicolumn{2}{c}{ Pressure $(\mathrm{MPa})$} \\
\cline { 2 - 3 } Strain & Start & End \\
\hline $5 \%$ & $0.166 \pm 0.108 * \#$ & $0.038 \pm 0.010 \#$ \\
$10 \%$ & $1.141 \pm 0.103 \#$ & $0.046 \pm 0.010 \#$ \\
$15 \%$ & $2.185 \pm 0.827$ & $0.035 \pm 0.026 \#$ \\
$20 \%$ & $3.548 \pm 0.429$ & $0.128 \pm 0.020$ \\
\hline
\end{tabular}

Data represents mean \pm standard deviation. $n=6$ for all groups. * Significantly different than $15 \%(p<0.05)$, \# significantly different than $20 \%(p<0.05)$.

frictionless finish, to ensure the sample is exposed to pure unconfined compression. Although we believe this bioreactor to be an improvement over others, we realize that there are some limitations that need to be compensated for. For example, this system can only perform unconfined compression currently. However, the system could be modified to run confined compression tests as well by outfitting a new plunger/well assembly.

Since the stress tests were conducted at 0.05 and $0.1 \mathrm{MPa}$, and resulted in strains between $2.6 \%$ and $20 \%$, the compliance of the system was negligible. Similarly, for the $5 \%$ strain control tests, the loads were small enough that the compliance of the system was negligible. However, for the $10 \%, 15 \%$ and $20 \%$ strain control tests, stresses were between 3.548 and $0.035 \mathrm{MPa}$. Thus, at the larger stress levels, the compliance of the system was greater. For instance, during the $10 \%$ strain control test, initially stress levels of 1.1 MPa would lead to approximately $57 \mu \mathrm{m}$ of compliance, and thus, for the first 150 of the $7200 \mathrm{~s}$ test, strains were closer to $8.8 \%$ instead of $10 \%$. For the $15 \%$ strain test, strains were closer to $13 \%$ for the first $200 \mathrm{~s}$

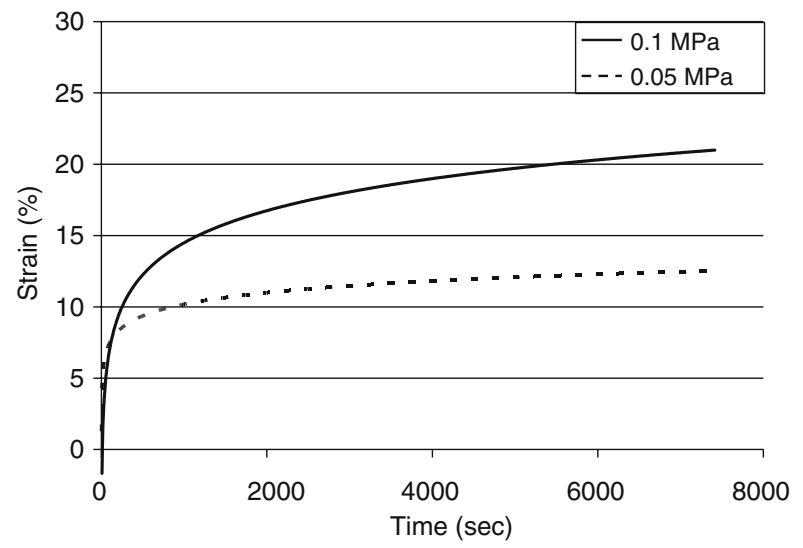

FIGURE 10. Strain vs. time for two representative load control tests. Only peak strain values during each loading cycle are plotted. Strain was calculated by dividing the peak displacement by the original height of the explant.
Table 3. Change in strains over the duration of the creep tests.

\begin{tabular}{lcc}
\hline & \multicolumn{2}{c}{ Strain (\%) } \\
\cline { 2 - 3 } Pressure $(\mathrm{MPa})$ & Start & End \\
\hline 0.05 & $2.6 \pm 0.53$ & $11.6 \pm 1.36$ \\
0.1 & $3.0 \pm 0.12$ & $20.7 \pm 1.45^{\star}$ \\
\hline
\end{tabular}

Data represents mean \pm standard deviation. $n=6$ for all groups

* Significantly different than $0.05 \mathrm{MPa}(p<0.05)$.

of the test, and as the material relaxed, the last $1 \mathrm{~h}$ and 57 min of the test were at $15 \%$ strain.

We hypothesized that PG breakdown (as determined by GAG in the media) would be high for both the underloading and overloading condition. PG breakdown was significantly increased at $20 \%$ strain. Meniscal tissue is a mechanically sensitive, and mechanical loading has been shown to regulate gene expression. ${ }^{14}$ Hence, we expected that loading the tissue below normal physiological levels of magnitude (underloading) would result in PG breakdown. Lack of increased PG breakdown for control samples (underloading) is surprising and needs to be further explored. Perhaps the degraded PG is not being released into the media for the control samples, whereas the overloaded samples have mechanical compression to help move the broken down PG into the media. Future studies will measure PG breakdown in the tissue explants following compression to determine the integrity of the PG within the tissue. These data suggest that removing $30-60 \%$ of meniscal tissue, and thereby increasing tissue strains over $15 \%$ results in an increase in PG breakdown and tissue destruction. Thus, not only does meniscectomy affect the underlying articular cartilage but the remaining meniscal tissue appears to begin to breakdown, possibly leading to a change in meniscal material properties. This data is supported by previous work that showed following an ACL transection, degenerative changes were seen in the meniscus prior to any articular cartilage changes. ${ }^{10}$

DiMicco et al. showed an increase in GAG release from bovine cartilage that had been exposed to an injurious level single uniaxial, unconfined compression. ${ }^{1}$ Inhibitors of biosynthesis or degradative enzymes did not affect PG breakdown, suggesting that the breakdown was a mechanical consequence of compression. GAG release 1-7 days post injury was slowed by metalloprotease inhibitors. Shin et al. ${ }^{12}$ showed that dynamic compression $(0.1 \mathrm{MPa}$ for $24 \mathrm{~h}$ at $0.5 \mathrm{~Hz}$ ) increased both GAG synthesis as well as release to the media compared to unloaded controls. Our loading scheme was designed to simulate approximate physiological walking conditions $(2 \mathrm{~h}, 1 \mathrm{~Hz})$. It is difficult to compare our GAG data to a study of a single injurious 
insult, or dynamic compression for $24 \mathrm{~h}$. We created an approximate daily physiological loading environment that might occur during walking, and simulated loads from unloaded to overloaded due to meniscectomy. In the future, we will investigate the mechanisms of GAG release, whether it is mechanical damage or activation of enzymatic activity.

It was surprising that explants tested at $0.05 \mathrm{MPa}$ showed greater PG breakdown than explants tested at $0.1 \mathrm{MPa}$ for the superficial zone. One possible reason for this result might be related to the cell viability. A compression of $0.1 \mathrm{MPa}$ may induce more cell death than $0.05 \mathrm{MPa}$ of compression and hence fewer cells may be available for production of metalloproteases that may contribute to the breakdown of PG. Current studies are underway to document the degree of cell death in the explants.

It is interesting to compare the load control results to the displacement control results. Based on Fig. 9, the $20 \%$ strain test applied an initially very high load $(\sim 3.5 \mathrm{MPa})$, but equilibrated at $0.1 \mathrm{MPa}$. Similarly, the $0.1 \mathrm{MPa}$ test reached a steady state of $20 \%$ strain (Fig. 10). Hence, we would expect to see similar levels of PG breakdown in the $20 \%$ strain test as well as the $0.1 \mathrm{MPa}$ test. This is also true for the $10 \%$ strain test and the $0.05 \mathrm{MPa}$ stress tests. For example, in the deep zone the $20 \%$ strain control test resulted in $3.7 \pm 1.4 \mathrm{ug} / \mathrm{ml}$ per gram of tissue, whereas the $0.1 \mathrm{MPa}$ test resulted in $1.9 \pm 0.5 \mathrm{ug} / \mathrm{ml}$ per gram of tissue. This large difference could be due to either "liftoff" (separation between loading platen and sample during a $1 \mathrm{~Hz}$ test) ${ }^{4}$ or the initially high stress that was reached initially in the $20 \%$ displacement control tests. In contrast to the differences seen above, the $10 \%$ strain test and $0.05 \mathrm{MPa}$ stress test resulted in $1.3 \pm 0.2$ and $1.8 \pm 0.5 \mathrm{ug} / \mathrm{ml}$ per gram of tissue, respectively. Previous 3-D computational studies of an entire human knee joint have shown that mean contact pressures changed from 1.57 MPa for an intact healthy meniscus to $3.09 \mathrm{MPa}$ following $60 \%$ meniscectomy. ${ }^{18}$ Maximum contact pressures on the superior surface of the meniscus changed from 4.7 to $7 \mathrm{MPa}$ when $60 \%$ of the meniscus was removed. ${ }^{18}$ The differences between stress and strain control studies noted above make the data presented difficult to interpret due to the nonphysiological nature of in vitro unconfined compression studies. Clearly, this indicates that meniscal tissue may respond differentially to stress versus strain, the duration of strain levels, or most likely the loading history. Before definitive clinical implications can be made regarding the effects of meniscectomy on meniscal tissue, we must first determine if the levels of PG breakdown noted in this study correspond to changes in the load-bearing capacity of the tissue and its function in the knee joint.
One of the limitations of this study is lack of investigation of differences between the medial and lateral menisci as well as specific location within the meniscus from which explants were harvested. This likely resulted in higher standard deviations. Future studies with a larger set of animals are proposed in which lateral versus medial, anterior versus posterior and inner radial versus outer radial differences could be studied. Previous researchers have shown a difference between inner and outer radial explants. ${ }^{14}$ Bisection of explants has previously been shown to release many growth factors. ${ }^{17}$ Since all samples in this study were bisected, the relative differences found are still significant. It should be noted that the measured response may be due not only to mechanical stimuli but also growth factors released due to cutting the samples. In addition to bisecting the samples, other factors, such as FBS concentration and post-incubation time may effect the absolute concentrations of GAG analyzed in this study. Therefore, only relative comparisons between treatment groups should be considered.

In summary, this simple and practical experimental system allows for reproducible application and quantification of homogeneous stresses or strains to explants tissues, thereby providing a systemic and quantitative method for correlating external mechanical stimuli to cellular and molecular mechanisms of mechanotransduction.

\section{ACKNOWLEDGMENT}

This study was supported by a Whitaker Foundation grant (RG-03-0047) to T.L. Haut Donahue. The authors would like to thank Steven Krage at the Mayo Clinic for procurement of the tissue samples.

\section{REFERENCES}

\footnotetext{
${ }^{1}$ DiMicco, M. A., et al. Mechanisms and kinetics of glycosaminoglycan release following in vitro cartilage injury. Arthritis Rheum. 50(3):840-848, 2004.

${ }^{2}$ Djurasovic, M., et al. Knee joint immobilization decreases aggrecan gene expression in the meniscus. Am. J. Sports Med. 26(3):460-466, 1998.

${ }^{3}$ Dowdy, P. A., et al. The effect of cast immobilization on meniscal healing. An experimental study in the dog. Am. J. Sports Med. 23(6):721-728, 1995.

${ }^{4}$ Evans, R. C. and T. M. Quinn. Dynamic compression augments interstitial transport of a glucose-like solute in articular cartilage. Biophys. J. 91(4):1541-1547, 2006.

${ }^{5}$ Farndale, R. W., D. J. Buttle, and A. J. Barrett. Improved quantitation and discrimination of sulphated glycosaminoglycans by use of dimethylmethylene blue. Biochim. Biophys. Acta. 883(2):173-177, 1986.

${ }^{6}$ Farndale, R. W., C. A. Sayers, and A. J. Barrett. A direct spectrophotometric microassay for sulfated glycosaminoglycans in cartilage cultures. Connect. Tissue Res. 9(4):247248, 1982.
} 
${ }^{7}$ Fink, C., et al. . The effect of dynamic mechanical compression on nitric oxide production in the meniscus. Osteoarthritis and Cartilage 9(5):481-487, 2001.

${ }^{8}$ Frank, E. H., et al. A versatile shear and compression apparatus for mechanical stimulation of tissue culture explants. J. Biomech. 33(11):1523-1527, 2000.

${ }^{9}$ Grodzinsky, A. J., et al. Cartilage tissue remodeling in response to mechanical forces. Annu. Rev. Biomed. Eng. 2:691-713, 2000.

${ }^{10}$ Hellio Le Graverand, M. P., et al. Early changes in lapine menisci during osteoarthritis development: Part I: cellular and matrix alterations. Osteoarthritis Cartilage 9(1):56-64, 2001.

${ }^{11}$ Sah, R. L., et al. Biosynthetic response of cartilage explants to dynamic compression. J. Orthop. Res 7:619-636, 1989.

${ }^{12}$ Shin, S. J., et al. Regulation of matrix turnover in meniscal explants: role of mechanical stress, interleukin-1, and nitric oxide. J. Appl. Physiol. 95(1):308-313, 2003.
${ }^{13}$ Spilker, R. L., P. S. Donzelli, and V. C. Mow. A transversely isotropic biphasic finite element model of the meniscus. J. Biomech. 25(9):1027-1045, 1992.

${ }^{14}$ Upton, M. L., J. Chen, and L. A. Setton. Region-specific constitutive gene expression in the adult porcine meniscus. J. Orthop. Res. 24(7):1562-1570, 2006.

${ }^{15}$ Upton, M. L., et al. Differential effects of static and dynamic compression on meniscal cell gene expression. $J$. Orthop. Res. 21(6):963-969, 2003.

${ }^{16}$ Vailas, A. C., et al. Adaptation of rat knee meniscus to prolonged exercise. J. Appl. Physiol. 60(3):1031-1034, 1986.

${ }^{17}$ Vincent, T. L., et al. Basic FGF mediates an immediate response of articular cartilage to mechanical injury. Proc. Natl Acad. Sci. USA 99(12):8259-8264, 2002.

${ }^{18}$ Zielinska, B. and T. L. Haut Donahue. 3D finite element model of medial meniscus meniscectomy; changes in contact behavior. J. Biomech. Eng. 128(1):115-123, 2006. 